\title{
USO DE ANÁLISE FÍSICA PARA ESTIMAR A COMPOSIÇÃo QUIMICA EM INGREDIENTES PARA RAÇÕES
}

\author{
H.da S. PASSOS JR ${ }^{1} \&$ M.L.V. BOSE ${ }^{2}$
}

\begin{abstract}
RESUMO: Procurou-se verificar se a medida física "densidade aparente" poderia ser utilizada como parâmetro capaz de analizar a composição química bromatologica dos farelos de algodão $40 \%$ (FA), de soja (FS) e de arroz cru (FAr), provenientes de diversas regiōes do país. Os tratamentos consistiram na adição das respectivas cascas de farelo aos níveis de $0,10,20,30,40,50$ e 100, simulando fraudes em delineamento inteiramente casualizado. As análises foram efetuadas no laboratório da Purina Nutrimentos Ltda, em Paulínea. Avaliou-se o efeito da adição crescente da casca sobre os valores de densidade, e desta sobre a composicāo em umidade (U), proteína bruta (PB), extrato etéreo (EE), fibra bruta (FB) e matéria mineral (MM). As amostras foram analisadas separadamente, pois apresentaram efeito de origem (P? 0,05) sobre a densidade de FA e FS, mas tendência positiva sobre a densidade do FAr. Verificou-se correlação alta da densidade com PB e FB de FS e FA ( $R^{2}$ ? 80 a 70\%, respectivamente). Com as demais determinações para o FAr não houve correlacão sinificativa. Exceto para FAr, a medida da densidade, de determinação rápida, fácil e barata; permite avaliação prévia do nível proteico e de adição de cascas nos dois suplementos proteicos mais utilizados no país.

Descritores: farelo de algodão, farelo de soja, farelo de arroz, densidade aparente, análise química bromatológica, análise física de alimento.
\end{abstract}

\section{THE USE OF PHYSICAL ANALYSIS TO ESTIMATE THE CHEMICAL COMPOSITION OF FEED INGREDIENTES.}

ABSTRACT: The purpose of this experiment was to verify if feed "bulk density" would be a good indication of chemical components of feeds such as $\mathbf{4 0 \%}$ crude protein cotton (C) and soybean (S) meals and rice bran (RB). The bromatological analysis as carried out at the central laboratory of Purina Nutrimentos Ltda., located at in Paulínia, State of São Paulo, Brazil. Samples of feed came from different locations of the country. Increasing proportions - zero, 10, 20, 30, 40, 50 and $100 \%$ - of hulls were added to $C, S$ and $R B$, as treatments, in a randomised experimental design. The addition of hulls influenced significantly $(P<0,05)$ the bulk density , in a negative way for $C$ and $S$, and in a positive way for RB. Bulk density was correlated to crude protein and fiber for $C$ and $S\left(R^{2}>70\right.$ and $80 \%$ respectively), but there was no correlation to any component of $R B$. Bulk density could also indicate fraudulence due to the addition of hulls to meals.

Index terms: cotton-soybean meals, rice bran, chemical feed analysis, bulk density, physical feed analysis.

\section{INTRODUÇÃo}

Análise química de alimentos parece indispensável, porém sua demora e seu custo elevados sugerem outras tentativas. É sabido que os suplementos protéicos básicos de rações, os farelos de soja e de algodão, bem como o farelo de arroz crú, são de qualidade tanto melhor quanto menor quantidade de cascas possuirem. Não bastasse a proporção natural de cascas, há ainda inclusão de cascas extras, adulterando o produto.
Utilização de análises físicas no controle de qualidade vem crescendo devido à facilidade, precisão e de seu baixo custo. A densidade aparente (peso da unidade de volume ocupado pelo alimento, ou massa de um volume unitário) guarda uma relação positiva com concentração energética, no caso de grãos de cereais. Entretanto, a textura ou tamanho das partículas, a força de atração inter-partículas, o número de pontos de contato, agentes anti-aglomerantes, são fatores que interferem sobre o valor da densidade, conforme

1 Zootecnista, aluno do CPG de Nutrição Animal e Pastagens. E.S.A. "Luiz de Queiroz", Piracicaba-SP>
${ }^{2}$ Professor Orientador, E.S.A. "Luiz de Queiroz", Departamento de Zootecnia, Piracicaba-SP. 


\section{RUMPF (1961) e WOODBURY \& WEINHEIMER} (1965).

A densidade aparente é índice eficiente de qualidade na seleção de noz pecan, conforme WALUG (1963); de batatas, conforme KLEINKOPF et al. (1987); de sementes de algodão, soja e arroz, conforme CHUMA, et al. (1981).

Partiu-se da hipótese de que a proporção de casca estaria refletida na densidade aparente em virtude da baixa densidade da fibra, abundante na casca. Poderia, ainda, haver correlação com componentes químico-bromatológicos, além da fibra, dispensando a correspondente análise química.

\section{MATERIAL E MÉTODOS}

Amostras de farelo de algodão (com $40 \%$ de proteína) de seis diferentes origens, de farelo de soja de sete origens, e de farelo de arroz de cinco origens, bem como casca de semente de algodão, de semente de soja e de semente de arroz, contituiram a matéria prima estudada.

Tratamentos: cada um dos farelos foi acrescentado de $10,20,30,40$ e $50 \%$ de casca da respectiva semente, além do farelo sem acréscimo de casca e de casca somente; ou seja: níveis zero, $10,20,30,40,50$ e $100 \%$ de casca (sete tratamentos).

\section{Determinações}

a) densidade aparente - a medida de volume foi feita através de proveta, sem compactação do material e sem alteração do tamanho das partículas, seguindo-se pesagem, sendo expressa em $\mathrm{g} / \mathrm{l}$.

b) análise química bromatológica convencional procedida conforme os métodos da Associação Oficial dos Químicos Agrícolas (AOAC) dos Estados Unidos, de 1970 , com pequenas adaptações locais.

Delineamento experimental e análise estatística esquema inteiramente causalizado com sete tratamentos, análise da variância e estudo de correlações entre as determinações.

\section{RESULTADOS E DISCUSSÃO}

Aumento de adição de casca interfere significativamente $(P<0,05)$ sobre a densidade aparente dos farelos.
Farelo de algodão $40 \%$ - encontrou-se significância $(P<0,05)$ na interferência dos valores da densidade em três das seis origens estudadas, mesmo assim os coeficientes de determinação $\left(R^{2}\right)$ não ultrapassaram $68,16 \%$. Houve correlação significativa entre densidade e proteína bruta para as amostras de todas as origens, com valores de $\mathrm{R}^{2}$ acima de $70 \%$ para cinco delas; em relação ao extrato etéreo, houve significância $(P<$ $0,01)$ apenas para duas origens, com valores de $R^{2}$ baixos (19,85 e $24,94 \%)$; fibra bruta, em função da densidade foi significante para todas as origens, com valores de $\mathrm{R}^{2}$ acima de $71 \%$ em três delas; em relação a matéria mineral, houve significância para todas as origens, contudo com valores de $\mathrm{R}^{2}$ baixos, apenas dois ultrapassando a $52,64 \%$. A tabela final traz os valores determinados.

Farelo de soja - Avaliação da umidade através da densidade não mostrou significância em duas das sete origens estudadas; nas demais, os valores dos coeficientes de determinação variam de 26,26 a $48,31 \%$, não oferecendo segurança.

Em relação a proteína bruta, para todas as origens foi alta a significância $(P<0,01) \mathrm{com} R^{2}$ acima de $88 \%$, mostrando viabilidade da medida de densidade para avaliar esse nutriente. O mesmo se deu em relação à fibra bruta, com valores de $\mathrm{R}^{2}$ superiores a $80 \%$. Quanto à matéria mineral, em cinco origens os valores de $\mathrm{R}^{2}$ foram abaixo de $66 \%$, mas altamente significativos $(P<0,01)$ em relação a todas as origens. A tabela final contém os resultados obtidos.

Farelo de arroz cru - $O$ uso da densidade aparente para explicar teores de água não apresentou significância em quatro das cinco origens estudadas, tendo significância em apenas uma, mas com valor de $\mathrm{R}^{2}$ abaixo de $60 \%$.

Em três das origens, os valores de $\mathrm{R}^{2}$ foram acima de $81 \%$ para proteína bruta em função da densidade, com alta significância $(P<0,01)$, porém todos os valores da densidade da casca pura foram superiores aos dos farelos puros; o mesmo se deu em relação ao extrato etéreo e à fibra bruta. Quanto à matéria mineral $\mathrm{em}$ relação à densidade, a significância foi alta para quatro origens $(P<0,01)$, porém o valor de $\mathrm{R}^{2}$ só ultrapassou a $70 \% \mathrm{em}$ um caso. Os resultados das análises encontraram-se na tabela final.

O comportamento do farelo de arroz não é análogo ao dos demais estudados, possivelmente devido à diferença de natureza física e de composição química bromatológica. Os farelos de algodão e de soja derivam 
Valores Médios da Determinações Físicas e Químicas

\begin{tabular}{||cccccccc||}
\hline Ingrediente & Adição & Densidade & Umidade & P.B. & E.E. & F.B. & M.M. \\
& casca $\%$ & $(\mathrm{~g} / 1)$ & $(\%)$ & $(\%)$ & $(\%)$ & $(\%)$ & $(\%)$ \\
\hline Far. Algodão & 0 & 608,0 & 11,13 & 38,19 & 1,37 & 20,67 & 5,41 \\
& 10 & 561,4 & 10,01 & 31,00 & 0,71 & 24,36 & 5,34 \\
& 20 & 554,7 & 10,08 & 30,00 & 0,89 & 25,44 & 4,94 \\
& 30 & 540,7 & 10,09 & 25,00 & 0,81 & 28,67 & 4,64 \\
& 40 & 532,9 & 10,23 & 22,45 & 0,98 & 29,77 & 4,23 \\
& 50 & 512,1 & 10,50 & 20,00 & 0,98 & 32,14 & 4,21 \\
& 100 & 480,6 & 11,07 & 4,00 & 1,53 & 42,32 & 2,96 \\
\hline Far. de Soja & 0 & 639,9 & 12,2 & 47,0 & 1,7 & 7,9 & 6,2 \\
& 10 & 531,4 & 10,7 & 41,7 & 0,9 & 13,2 & 5,8 \\
& 20 & 483,0 & 10,6 & 38,4 & 1,0 & 15,7 & 5,5 \\
& 30 & 452,5 & 10,5 & 35,0 & 1,1 & 19,1 & 5,5 \\
& 40 & 410,2 & 10,3 & 30,8 & 1,1 & 22,2 & 5,2 \\
& 50 & 372,2 & 10,3 & 27,2 & 1,1 & 26,2 & 5,3 \\
& 100 & 300,4 & 10,5 & 10,2 & 1,3 & 42,8 & 5,7 \\
\hline Far. de Arroz & 0 & 328,7 & 11,97 & 14,50 & 16,10 & 10,97 & 7,53 \\
& 10 & 320,3 & 9,89 & 13,44 & 13,70 & 15,88 & 8,37 \\
& 20 & 321,3 & 9,77 & 12,67 & 13,79 & 18,55 & 9,14 \\
& 30 & 322,5 & 9,83 & 10,78 & 9,74 & 22,58 & 10,21 \\
& 40 & 326,1 & 9,67 & 9,93 & 9,19 & 27,81 & 11,08 \\
& 50 & 329,3 & 9,59 & 8,71 & 6,88 & 31,92 & 11,89 \\
& 100 & 363,3 & 9,77 & 2,57 & 0,53 & 51,73 & 13,23 \\
\hline
\end{tabular}

$\mathrm{PB}=$ proteína bruta; $\mathrm{EE}=$ extrato etéreo $\mathrm{FB}=$ fibra bruta $; \mathrm{MM}=$ matéria mineral

da extração do óleo das sementes, enquanto o de arroz só contém a parte externa da semente e pequena proporção de endosperma. Contudo, a inclusão de casca de arroz ao respectivo farelo tem restrição de origem sanitária, devido ao efeito deletérico de sílico em teor elevado, conforme BOSE (1990).

\section{CONCLUSÕES}

Uma vez que com os farelos de algodão e de soja verificou-se efeito da adição de casca sobre a densidade aparente e relação entre esta determinação e os teores de proteina e fibra brutas, confirmou-se a hipótese inicial da primeira determinação prestar-se para controle inicial de qualidade daqueles alimentos. A mesma determinação não se mostrou efetiva para o farelo de arroz cru. A origem influenciou sobre os três alimentos estudados, podendo limitar a generalização dos resultados positivos.

\section{REFERENCIAS BIBLIOGRÁFICAS}

Association of the Offical analytical Chemists. Oficial methods of analysis. 11. ed. Washington, AOAC, $1970,1015 \mathrm{p}$. 
BOSE, M. L. V. Concentrados energéticos. In: PEIXOTO, A. M., ed. et al. Alimentação de bovinos de corte. Piracicaba, FEALQ, 1990. p. 203-16.

CHUMA, Y.; UCHIDA, S.; SHENSANGA, K. H. H. Bulk physical and thermal properties of cereal grains as affected by moisture content. Food Science and Tecnology / LebensmittelWissenschaft und - Technologie, London, 13(4) 57-70, 1981.

KLEINKOPF, G.E.; WESTERMANN, D.T.; WILLE, M.J.; KLEINSCHMIDT, G.D. Specific gravity of Russet Burbank potatoes. American Potato Journal, Orono, 64: 579-87, 1987.

RUMPH, $H$. The strenght of granules and agglometes in agglome ration. New York, W.A. Knepper, 1980.

WAUGH, J.G. Approximate specific gravity determination. Industrial and Engineering Chemistry . Analitical Edition, Washington, 10 (1): 209-12, 1938.

WOODBURY, G. W. \& WEINHEIMER, W.H. Specific gravity - solids correlations in Russet Burnbank with respect to point of origin and storage history. American Potato Journal, Orono, 42: 98-104, 1965. 